\title{
Cidadania e urbanismo: políticas de acessibilidade para pessoas com deficiência ou mobilidade reduzida em Franca-SP
}

Citizenship and urbanism: accessibility policies for people with disabilities or reduced mobility in Franca-SP

\section{André Luiz Pereira Spinieli spinieliandre@gmail.com}

Mestrando em Direito - UNESP Franca

\begin{abstract}
Resumo
Partindo do método bibliográfico e documental, o objetivo deste trabalho é analisar as políticas públicas de acessibilidade e mobilidade urbana às pessoas com deficiência ou mobilidade reduzida no município de Franca, no interior do estado de São Paulo, enquanto instrumentos que fomentam o acesso a outros direitos fundamentais e como medida necessária à promoção do direito à inclusão social dos grupos vulneráveis.

Palavras-chave: acessibilidade urbana; pessoas com deficiência; políticas públicas; Franca.
\end{abstract}

\begin{abstract}
Based on the bibliographic and documentary method, the objective of this paper is to analyze the public policies of urban accessibility and mobility to people with disabilities or reduced mobility in the municipality of Franca, interior of the state of São Paulo, as instruments that foster access to other fundamental rights and as a necessary measure to promote the right to social inclusion of the vulnerable groups.
\end{abstract}

Keywords: urban accessibility; disabled people; public policy; Franca. 


\section{Introdução}

Assistida a partir dos avanços tecnológicos, políticos e sociais empregados pelas concatenadas revoluções industriais nos últimos séculos, a organização da sociedade desde então, necessariamente, perpassa pelo processo de racionalização das estruturas urbanísticas, motivo pelo qual especificamente os últimos cem anos foram considerados o "século da urbanização". Foi justamente nesse período que se operaram notórias mudanças no pensamento sobre a cidade, afastando-se da concepção meramente espacial para atingir um aspecto voltado às demandas sociais, o que põe em foco as reivindicações de grupos vulneráveis e minorias, especialmente as pessoas com deficiência, principal agrupamento atingido em virtude da inadequação do espaço urbano.

A conformação das relações sociais contemporâneas tem revelado no campo acadêmico que as pessoas com deficiência ou com mobilidade reduzida ${ }^{1}$ são vítimas de uma cultura pósviolatória dos direitos humanos e fundamentais² (SÁNCHEZ RUBIO, 2015), vez que, especificamente no ambiente urbano em geral, elas não apenas são frequentadoras de espaços inadequados em termos de acessibilidade arquitetônica, como também são reiteradamente expostas a situações qualificadas como discriminatórias. Trata-se verdadeiramente de uma posição pós-violatória dos direitos humanos do grupo em questão, pelo fato de que apenas se pensa nas possíveis soluções após o acontecimento que origina lesões aos direitos das pessoas com deficiência.

Para além das diferenciações sociais que são geralmente traduzidas em discriminações negativas, preconceitos, observam-se outras formas de preconceito em face da relação travada

\footnotetext{
1 Com a reforma operada no âmbito da legislação infraconstitucional aplicável originariamente às pessoas com deficiência, também se observa a inclusão normativa das pessoas com mobilidade reduzida. Em realidade, não se pode tratar pessoas com deficiência e com mobilidade reduzida como sendo agrupamentos idênticos ou que se complementam, não obstante os direitos aplicáveis no âmbito da tutela jurídica nos espaços urbanos sejam parcialmente similares. Nos termos da legislação em vigor, especificamente no Estatuto da Pessoa com Deficiência, compreende-se por pessoa com mobilidade reduzida "aquela que tenha, por qualquer motivo, dificuldade de movimentação, permanente ou temporária, gerando redução efetiva da mobilidade, da flexibilidade, da coordenação motora ou da percepção, incluindo idoso, gestante, lactante, pessoa com criança de colo e obeso" (BRASIL, 2015). Para os fins deste trabalho, ainda que sejam citadas as pessoas com mobilidade reduzida pelos motivos de similaridade das questões enfrentadas em termos de efetividade de direitos humanos, alerta-se que apenas as pessoas com deficiência constituem sujeitos da pesquisa.

2 De acordo com o professor David Sánchez Rubio (2015), a cultura jurídica contemporânea concebe os direitos humanos a partir de uma cultura pós-violatória, o que significa dizer que a concepção material desses direitos ocorre tão somente após sua violação, por meio do acesso à justiça. Todavia, como decorrência dessa dimensão, boa parte das demandas não chega aos tribunais e isso fomenta uma anestesia na proteção dos direitos humanos. É dizer que há uma preocupação de cunho estatal e formal, mas, em contrapartida, o nível de eficácia material dos direitos humanos é mínimo.
} 
entre as pessoas com deficiência e as barreiras arquitetônicas e urbanísticas dispostas nas cidades brasileiras. Por tal motivo, faz-se necessário visualizar o espaço urbano como ambiente propício para se pensar e fomentar a criação de novas demandas por direitos das pessoas com deficiência, gênese que se dá a partir de negações de acesso aos direitos e pela participação efetiva em sociedade de novos grupos que buscam tal concretização em zonas de conflito organizadas pela exclusão histórica e social.

A partir da constatação empírica ofertada por numerosas pesquisas acadêmicas, verificase que os espaços urbanos brasileiros na contemporaneidade não se encontram aptos a possibilitar a fruição plena dos direitos e garantias fundamentais por parte das pessoas com deficiência ou com mobilidade reduzida, não se olvidando dos significativos esforços que permanecem em voga no âmbito social e no projeto institucionalizado, em busca de uma inclusão social efetiva.

Dessa forma, a proposta deste trabalho é apresentar inicialmente uma reflexão sobre os avanços políticos, institucionais e jurídicos em termos de acessibilidade e mobilidade urbana ${ }^{3}$ para pessoas com deficiência ou mobilidade reduzida, destacando a passagem de uma filosofia social da invisibilidade para o movimento de inclusão social, que necessariamente leva em consideração tal faceta dos direitos desses grupos vulneráveis. Em segundo lugar, aborda-se brevemente as políticas públicas de acessibilidade urbana presentes no município de Franca, no interior do estado de São Paulo, dando ênfase aos principais aspectos que fomentam a inclusão urbana dessas pessoas.

\footnotetext{
${ }^{3}$ Há diferenças marcantes no conteúdo dos termos "acessibilidade" e "mobilidade", embora ambos os conceitos sejam aplicáveis na tutela jurídica da pessoa com deficiência nos ambientes urbanísticos. Inicialmente, tem-se que a acessibilidade é considerada a "possibilidade e condição de alcance para utilização, com segurança e autonomia, de espaços, mobiliários, equipamentos urbanos, edificações, transportes, informação e comunicação, inclusive seus sistemas e tecnologias, bem como de outros serviços e instalações abertos ao público, de uso público ou privados de uso coletivo, tanto na zona urbana como na rural, por pessoa com deficiência ou com mobilidade reduzida" (BRASIL, 2015). Tratase, portanto, da implementação de produtos e serviços que tenham por finalidade possibilitar às pessoas com deficiência em geral e às pessoas com mobilidade reduzida o acesso a espaços públicos no âmbito das cidades, conforme recorte teórico deste trabalho. Por outro lado, embora não conste conceito específico na legislação brasileira, a noção de mobilidade está vinculada à possibilidade de pessoas com deficiência ou mobilidade reduzida se movimentarem, como capacidade de grupo ou indivíduo de mudar de local de residência, de trabalho ou de se mover fisicamente de um lugar para outro (MORRIS; DUMBLE; WIGLE, 1979). Essa análise conceitual permite tecer conclusão no sentido de que acessibilidade e mobilidade são categorias complementares, uma vez que a mobilidade permite que as pessoas com deficiência ou mobilidade reduzida vão de um lugar para outro e a acessibilidade, por seu turno, possibilita o acesso aos serviços e produtos dispostos nesses locais.
} 


\section{Acessibilidade e mobilidade nos ambientes urbanos: da invisibilidade à inclusão da pessoa com deficiência ou mobilidade reduzida}

Contrariamente ao que facilmente se observava em outros períodos da história humana, as cidades contemporâneas não mais permanecem estanques às questões puramente arquitetônicas ou de ordem urbanística como um todo, mas também apresentam uma série de processos que entrelaçam cidade e sociedade, ou seja, os aspectos urbanísticos são postos em contato direto com a percepção social, analisando as cidades sob sua multiplicidade de facetas. As cidades brasileiras foram tomadas por determinada complexidade, sendo possível notar que a maioria delas não se encontra apta a receber pessoas com deficiência ou com mobilidade reduzida, dada a dificuldade presente no acesso aos produtos e serviços dispostos no ambiente urbano, diante da ausência de um projeto de acessibilidade adequado a proporcionar o gozo de direitos fundamentais por essas pessoas.

As dificuldades enfrentadas pelas pessoas com deficiência no âmbito das cidades não se limitam às edificações ou aos elementos propriamente urbanos, cuja responsabilidade constitucional por garantir a adequação pertence exclusivamente ao poder público, como os transportes ou prédios públicos. Em realidade, soma-se a essa problemática a existência de barreiras tipicamente sociais, que são reveladas na medida em que a sociedade vivente nos ambientes urbanos possui pouca ou mesmo nenhuma preocupação com o reconhecimento do outro, notadamente o outro com deficiência, tal como o descaso frente à necessidade de políticas de acessibilidade e inclusão social. Tais barreiras sociais, que também podem ser caracterizadas como reflexo de uma atitude construída culturalmente, impedem que a sociedade de maneira geral enxergue a necessidade e a importância de impulsionar o processo de inclusão social das pessoas com deficiência. Há uma indiferença culturalmente condicionada, que rejeita qualquer tipo de diversidade e, consequentemente, nega a dimensão antropológica do princípio da dignidade, aspecto ainda notório nas sociedades contemporâneas.

A propósito, pensar os processos de inclusão social das pessoas com deficiência exige trabalhar o tema como uma via de mão dupla. Isso significa afirmar que, se, por um lado, os integrantes do grupo vulnerável em questão devem atuar como verdadeiros protagonistas desse encadeamento de ocorrências que os retiram da invisibilidade social e os colocam sob a égide de um Estado Democrático e Social de Direito, por outro, a sociedade deve deixar de lado todos seus preconceitos e estigmas criados contra as pessoas com deficiência e auxiliá-los na construção desse novo estado de cidadania. 
Retirando a pessoa com deficiência das margens de um processo histórico de exclusão, os documentos constitucionais e convencionais contemporâneos têm por foco o oferecimento de políticas que contemplem o aspecto da maior liberdade pessoal possível no âmbito das ações desempenhadas pelas pessoas com deficiência em sociedade. Não por acaso é que as normativas nacionais e internacionais de proteção direta desse grupo vulnerável exigem expressamente que a formatação de elementos comuns na vida urbana, por exemplo, seja dotada de caracteres que permitam o gozo dos direitos fundamentais com máxima autonomia, segurança, independência e comodidade.

Nesse sentido, sobre o conceito de autonomia em direitos humanos, afirma o professor David Sánchez Rubio (2015, p.114) que se trata da possibilidade de passar de ações que demandam menor controle, as alienantes, para experiências de maior controle, as libertadoras, como forma de recuperar outras dimensões e elementos de direitos humanos capazes de instituir sujeitos ativos e soberanos de tais direitos. Não seria outro o motivo pelo qual a vocação originária dos direitos humanos é oportunizar a autonomia dos sujeitos sociais, que se relaciona à faculdade que o ser humano possui de identificar, denunciar e lutar contra qualquer possibilidade que dificulte ou impossibilidade o usufruto desses direitos.

Operada a transição no âmbito da filosofia social, quanto ao modelo de enfrentamento das questões atinentes à fruição de direitos pelas pessoas com deficiência, que vai da completa invisibilidade - momento em que são considerados indivíduos cujas vidas não mereciam ser vividas e quando há a adoção legítima de práticas excludentes - aos meandros do movimento de inclusão social, pode-se afirmar que os direitos humanos das pessoas com deficiência são produtos de significativas lutas sociais, individuais e diárias. Conforme assevera o professor David Sánchez Rubio (2015, p.114-5), os direitos humanos são necessariamente produtos de diversos processos de luta engendrados com o objetivo de consolidar espaços de liberdade e dignidade humanas. Por esse motivo, transpondo as considerações do pensamento crítico dos direitos humanos para a tutela jurídico-social das pessoas com deficiência, podem ser compreendidos como o complexo de ações sociopolíticas, culturais, institucionais e jurídicas assumidas pelos homens na proporção em que reagem aos excessos de poder que impeça os grupos vulneráveis de se autoconstituírem enquanto conjuntos de pessoas humanas dotadas dos atributos da dignidade e liberdade, como sujeitos de uma "pluriversalidade".

Compreender a estrutura constitutiva dos direitos das pessoas com deficiência é condição indispensável para se pensar criticamente a cidade acessível como parte de um conjunto maior de direitos civis, sociais, econômicos, culturais, difusos e coletivos necessários à tutela jurídica, 
política e social integralista das pessoas com deficiência, tudo a partir de uma realidade conforme os parâmetros de acessibilidade. Contemporaneamente, a partir de uma concepção baseada no senso comum, enquanto valor sociogênico, facilmente poderia se afirmar que a garantia de acessibilidade em um ou mais espaços urbanos frequentados pelas pessoas com deficiência seria suficiente para exaurir o conteúdo desse direito.

Não se trata tão somente de implementar as medidas em um ou outro espaço da cidade, comumente naqueles mais frequentados pelas pessoas com deficiência, mas sim ampliar o projeto urbano a ponto de estabelecer marcas de uma acessibilidade notória e que contemple toda e qualquer espécie e grau de deficiência. O projeto de acessibilidade deve ser amplo o bastante para que possa abranger todo o caminho percorrido pela pessoa com deficiência nas cidades. Pode-se exemplificar isso a partir de ilustração na qual não basta, para fins de efetivação dos direitos humanos dessas pessoas, que o transporte público seja acessível, se todo o entorno - ruas, calçadas, escadas, banheiros e outros - não possui a mesma dimensão de acessibilidade.

A partir da participação das pessoas com deficiência em sociedade é que se busca minimizar os efeitos negativos apresentados pelas barreiras que afetam diretamente a dignidade humana e a qualidade de vida dessas pessoas no âmbito urbano. As políticas públicas que assegurem a participação desses agentes protagonistas de uma luta social fundamentam um complexo de direitos humanos que têm por objetivo buscar o respeito às diversidades e o reconhecimento sociojurídico dos grupos vulneráveis. Isso resta evidente a partir do texto da Convenção Internacional sobre os Direitos das Pessoas com Deficiência, que afirma a necessidade de os Estados agirem em prol desse grupo vulnerável e assegurar o acesso aos meios físicos e aos transportes, além de outros, em igualdade de oportunidades para com as demais pessoas (BRASIL, 2009).

Os fenômenos da acessibilidade e mobilidade urbanas para pessoas com deficiência são deveras complexos e abrangem diversos fatores que fogem das balizas formativas das cidades, atingindo, também, questões afins ao dispêndio de verbas públicas para os projetos de adequação dos espaços e demais elementos públicos nas cidades, cujo principal inimigo à efetivação é o crescimento demográfico e a urbanização desordenada. Apenas se faz possível falar em inclusão social da pessoa com deficiência no ambiente urbano ao passo em que se fizerem presentes medidas de acessibilidade que garantam a autonomia dessas pessoas.

Portanto, diante do desenvolvimento descompassado das cidades brasileiras, cujo crescimento demográfico e espacial não leva em consideração as necessidades específicas de 
grupos que se encontram abarcados por seus limites, como as pessoas com deficiência, apenas com instrumentos de política pública social é que se poderá assegurar, de forma efetiva, os direitos humanos das pessoas com deficiência.

\section{Pessoas com deficiência ou mobilidade reduzida como sujeitos das políticas públicas de acessibilidade na cidade de Franca-SP}

Parte da essencialidade das sociedades contemporâneas está no fato de que suas principais atividades são desenvolvidas em ambiente urbano. Em comparação com a atividade campestre, favorece-se diretamente o levantamento, por um lado, de aspectos positivos, como maior possibilidade de acesso a produtos e serviços, englobando o exercício de direitos fundamentais sociais, e, por outro, de aspectos negativos, como a evidenciação das vulnerabilidades. Tratase de uma situação de risco pessoal e social, que se volta à ausência de serviços básicos especializados nas limitações apresentadas por determinados grupos, notadamente aqueles tidos como vulneráveis ou minoritários.

Buscando uma conceituação macro do que se entende por vulnerabilidade social, Rubens Adorno (2001, p.62) especifica que a expressão "sintetiza a ideia de uma maior exposição e sensibilidade de um indivíduo ou de um grupo aos problemas enfrentados na sociedade", como forma de crítica às dificuldades apresentadas por determinados sujeitos em relação ao acesso a serviços sociais primordiais. Transplantando a temática para a relação das pessoas com deficiência com os desafios apostos pelo urbanismo, tem-se que a existência de um quadro de vulnerabilidade social está intimamente relacionada à estrutura deficitária e desigual de serviços e objetos disponíveis para a garantia da acessibilidade dessas pessoas.

Neste campo assimétrico das relações sociais, os grupos vulneráveis se tornam potenciais vítimas de discriminações negativas e falhas quanto à formulação de políticas públicas ${ }^{4}$ capazes de satisfazer, de forma devida, as necessidades individuais e coletivas dos integrantes desses agrupamentos. Como afirmado anteriormente, as pessoas com deficiência partilham desse cenário de carência em relação à efetividade material, visível, de seus direitos humanos, vez

\footnotetext{
4 Nas palavras de Eduardo Appio (2006, p.136), as políticas públicas em geral podem ser compreendidas como sendo "instrumentos de execução de programas políticos baseados na intervenção estatal na sociedade com a finalidade de assegurar igualdade de oportunidades aos cidadãos". A partir desta leitura, percebe-se que as políticas públicas brasileiras, independentemente da natureza - seja ela de cunho econômico ou social -, possuem uma finalidade em comum, consistente na tentativa de assegurar condições dignas de existência aos cidadãos: o mínimo vital.
} 
que a racionalidade pós-violatória de tratamento possibilita a adoção de políticas úteis tão somente após a ocorrência de uma transgressão de direitos. Pensar a proposta reparação pósviolatória de transgressões aos direitos humanos das pessoas com deficiência no âmbito urbanístico corresponderia a afirmar que a existência de fatores de vulnerabilidade retira o caráter de sujeitos de direitos universais, quando, em realidade, tais elementos devem servir como balizas para que o Estado e a sociedade, de forma ampla, prezem por tutelas mais específicas às pessoas com deficiência e que estejam voltadas à superação das barreiras sociais e urbanísticas enfrentadas por tais pessoas.

A complexidade do tema ganha ainda mais relevância na medida em que se percebe que boa parte dos problemas relacionados à efetividade de direitos humanos das pessoas com deficiência nas cidades está fundada na dificuldade de se prover a acessibilidade de modo geral a serviços considerados essenciais à pessoa humana, notadamente os direitos sociais em sentido amplo, dos quais se destaca a falha infraestrutural do acesso aos transportes públicos. É válido recordar que a questão da acessibilidade e mobilidade urbana é essencial para a efetivação dos direitos das pessoas com deficiência, haja vista a impossibilidade de se "pensar em exercício de direitos, caso as pessoas não possam se deslocar dentro do espaço urbano" (CARVALHO, 2017, p.48).

A partir de primeiros olhares feitos de forma ampla e superficial, embora os municípios brasileiros tenham investido parte de seus recursos em políticas de acessibilidade para pessoas com deficiência, com tônica na tutela específica da deficiência física, fato é que a questão da garantia da mobilidade para essas pessoas como decorrência lógica da construção de espaços acessíveis ainda é desafio inconcluso. Conforme pondera Leonardo Souto (2006, p.73), “(...) podemos destacar o planejamento urbano de algumas prefeituras que estão se preocupando com a facilidade de locomoção, levando-se em consideração as possíveis limitações”, o que se torna materialmente visível a partir da instalação de calçadas rebaixadas, transportes públicos com rampas de acesso e espaços com medidas suficientes para a livre locomoção do deficiente físico.

A pauta da promoção de adequações às estruturas urbanísticas em nome da efetivação de direitos das pessoas com deficiência não constitui elemento prioritário nas agendas executivas municipais ou mesmo fator bem ranqueado na esfera das políticas públicas para grupos vulneráveis. Os problemas relativos ao afastamento do poder público municipal frente às necessidades das pessoas com deficiência eram verificáveis na cidade de Franca, no interior do estado de São Paulo, antes das medidas legislativas e de políticas públicas levadas a cabo pela administração local. Hoje, a cidade conta com aproximadamente 350.400 habitantes e é 
conhecida pelo desenvolvimento histórico e econômico baseado na indústria couro-calçadista, pelo sucesso da equipe de basquete e, por fim, pela qualidade do saneamento básico, que ofertou à cidade o primeiro lugar na lista brasileira de municípios.

Conforme trabalhado em dissertação por Anivaldo Carvalho (2017), o transporte público acessível para pessoas com deficiência física passou a ser ofertado na cidade de Franca durante o ano de 2001, como fruto das obrigações contraídas pela administração pública a partir das normas técnicas que entravam em vigor sobre o tema e, sobretudo, da Lei $\mathrm{n}^{\circ} 10.098$, de 2000, responsável por criar uma política de acessibilidade, com normas e critérios básicos para o atendimento dos caracteres mínimos.

Todavia, mesmo anteriormente à aprovação da lei federal, no âmbito de um contexto social de promoção da inclusão social da pessoa com deficiência a partir das adequações arquitetônicas, a administração pública francana colocou em prática políticas sociais em prol desse grupo, consistentes na implantação de, aproximadamente, quatrocentas rampas (CARVALHO, 2017, p.78). Na sequência cronológica, a implementação normativa destas medidas se deu no ano de 2006, quando foi aprovada a Lei Municipal $n^{\circ} 6.621$, que trata da obrigação de introdução de rebaixamento das calçadas quando de suas construções, de tal maneira que possa facilitar o acesso da pessoa com deficiência física a outros serviços (FRANCA, 2006).

Dessa forma, a crítica comumente feita à gestão pública do município de Franca não guarda relação necessariamente com eventual omissão ou ação incorreta da administração, o que deve ser objeto de significativo reconhecimento, pois se trata "de um dos raros casos brasileiros em que a ação governamental aconteceu anteriormente à sua obrigação legal" (CARVALHO, 2017, p.78), invertendo a concepção pós-violatória dos direitos humanos das pessoas com deficiência para trazer a lume uma proposta de atuação anterior a qualquer violação. A problemática levantada diz respeito à demora na chegada de instrumentos devidamente adaptados à cidade, como a vinda da frota de transportes públicos (ônibus) acessíveis apenas em 2008, oito anos depois da entrada em vigor da lei federal que ordenava a construção de espaços e bens dotados de acessibilidade.

Comentado por Anivaldo Carvalho (2017, p.78), “cada um destes ônibus conseguia (consegue) transportar apenas um cadeirante". Além disso, a problemática se agrava na medida em que vem à tona ser o critério utilizado pela empresa responsável pelo transporte público na cidade, a Empresa São José, para decidir em quais bairros haverá ou não o trânsito de ônibus acessíveis, um recorte puramente baseado em elementos de maior ou menor concentração 
populacional. O mesmo autor evidencia esse impasse ao afirmar que “(...) as pessoas com deficiência motora, que residiam em outras regiões da cidade, não poderiam utilizá-los em seus trajetos, a não ser que se deslocassem até o local de embarque" (CARVALHO, 2017, p.81). Não obstante os significativos avanços na proteção social da pessoa com deficiência no município em discussão, percebe-se que ainda persiste o problema do número de vagas disponíveis para tais pessoas no interior de transportes públicos coletivos, ainda que haja carros próprios da mesma empresa responsável que fazem o transporte específico das pessoas com deficiência.

A acessibilidade insuficiente não se limita aos transportes públicos ou ao acesso a calçadas, abrangendo, também, prédios públicos que não dispunham de qualquer perspectiva de acesso a pessoas com deficiência. No mês de dezembro de 2007, o jornal de maior circulação na cidade, Comércio da Franca (GCN), publicou matéria intitulada "Fórum, delegacia ou museu: proibidos para deficientes", na qual denuncia a falta de acessibilidade em construções públicas, dentre as quais se destacam aquelas vinculadas, de alguma forma, ao sistema de justiça. Há, notadamente, uma contradição: os poderes constituídos, inclusive o sistema judiciário, rogavam pelo cumprimento das diretrizes federais de acessibilidade para pessoas com deficiência, mas se mostravam insensíveis perante a temática e a necessidade dos cidadãos francanos com algum tipo de deficiência.

Os relatos trazidos na matéria jornalística apresentam o seguinte teor:

Um deficiente que for réu, testemunha ou jurado em algum processo no Fórum
de Franca dificilmente terá condição de chegar com suas muletas ou cadeira
de rodas até a sala do júri. Também terá dificuldades em conseguir falar com
promotores e juízes, a não ser que obtenha ajuda ou que os magistrados
desçam para atendê-lo, o que não é muito provável. O mesmo se repete na
Delegacia Seccional, onde a sala do delegado-chefe e algumas repartições
administrativas estão situadas no segundo andar e, como no fórum de Justiça,
o único acesso é por escadas. No Museu Histórico, no Centro, prédio do final
do século 19, que também já abrigou o Judiciário e a sede da Polícia Civil, até
hoje ainda não há como um deficiente físico chegar a sua parte superior. Assim
sendo, não é exagero dizer que não há cultura para deficientes em Franca. Pelo
menos não no Museu Histórico. (COMÉRCIO DA FRANCA, online, 2007).

Como afirmado, a matéria veiculada no jornal local evidencia não apenas a condição das muitas acessibilidades à pessoa com deficiência no ambiente urbano de Franca, mas também põe em cheque as próprias funções do Ministério Público e do Poder Judiciário locais, que, constitucionalmente incumbidos da missão de garantir a proteção jurídica, difusa ou coletiva, 
dos grupos vulneráveis e proporcionar a amplitude do direito de acesso à justiça, respectivamente, simplesmente liquidavam quaisquer possibilidades de uma pessoa com deficiência se ver bem recebida ou mesmo atendida quando necessitada dos serviços de tais instituições.

Embora as ruas da cidade estivessem preenchidas por aspectos visíveis de adequação arquitetônica, como fruto das medidas legais adotadas nos âmbitos federal e municipal, ainda eram precárias as condições de órgãos públicos no que tange à possibilidade de acesso pela pessoa com deficiência. Porém, passado algum tempo desde a entrada em vigor das leis municipais que buscavam a garantia de acessibilidade, as condições arquitetônicas desses espaços públicos foram drasticamente alteradas, de modo que hoje é possível falar em uma garantia do direito à acessibilidade por órgãos responsáveis, legal e socialmente, pela proteção desse grupo vulnerável. Esse conjunto de mudanças levou em consideração a colocação de salas de audiência e gabinetes dos magistrados no térreo do Fórum, tal como a necessidade de estar a Promotoria de Justiça à tutela da pessoa com deficiência localizada no piso térreo do prédio ministerial.

Ainda sobre o aspecto institucional de proteção das pessoas com deficiência, tem-se que no início dos anos 2000 foi promulgada lei municipal que instituía o Conselho Municipal da Pessoa com Deficiência (CMPCD), órgão vinculado e diretamente subsidiado pela Prefeitura Municipal de Franca. As atribuições do Conselho flutuam em torno da formulação de diretrizes da política de atendimento municipal às pessoas com deficiência, de acordo com as particularidades de cada indivíduo, além da promoção de campanhas e programas que tenham por finalidade educar em direitos humanos, sensibilidade e respeito aos direitos dessas pessoas. No mesmo sentido, criou-se a Associação de Deficientes Físicos de Franca e Região (ADEFI), cuja proposta de trabalho está focada, dentre outros assuntos, na reabilitação para que a pessoa com deficiência possa exercer ofícios e profissões diversas.

Além das alterações materiais realizadas nos anos 2000 no ambiente urbano francano, mais recentemente, no primeiro semestre de 2016, a Câmara Municipal de Franca aprovou projeto de lei que obriga a Prefeitura a implementar medidas para rebaixar as guias das calçadas em locais onde forem postas vagas preferenciais de estacionamento para pessoas com deficiência. O projeto de lei aprovado se convolou na Lei Complementar $n^{\circ} 271$, de 2016, que altera dispositivos de legislação anteriormente em vigor para introduzir a obrigatoriedade de implantação de rebaixamento de calçadas em locais onde se observar vagas reservadas de estacionamento para pessoas com deficiência ou mobilidade reduzida (FRANCA, 2016). Em 
2019, a Prefeitura também encetou esforços para aprovar o Plano de Mobilidade Urbana (PlanMob) da cidade, cuja finalidade é justamente orientar ações para fornecer uma acessibilidade responsável para pessoas com deficiência ou mobilidade reduzida (FRANCA, 2019).

De maneira geral, a tratativa da pessoa com deficiência na cidade de Franca não apresentou severas alterações desde o aparecimento dos marcos políticos, jurídicos e institucionais de cada período da história da cidade. Significa dizer que os problemas relativos à garantia de acessibilidade plena e respeito aos direitos humanos dessas pessoas ainda se fazem presentes na sociedade francana, possivelmente por uma questão cultural característica das pequenas cidades interioranas de não reconhecimento e vivência cotidiana com a diversidade, o que leva à adoção, por parte do poder público municipal, de políticas públicas tímidas e que não surtem efeito indiscriminado. Ao menos, não por tempo relevante.

\section{Considerações finais}

Pensar a cidade inclusiva sob o viés da efetividade dos direitos humanos das pessoas com deficiência é parte do raciocínio acadêmico lançado sobre os movimentos de materialização dos direitos à acessibilidade e mobilidade urbana, enquanto faceta fundamental do princípio da isonomia e do direito à cidade. Em suma, observou-se por meio deste trabalho que a reflexão crítica sobre a realização dos direitos humanos das pessoas com deficiência se dá evidentemente de forma pós-violatória, ocorrendo uma salvaguarda desses direitos tão somente após transgressões na ordem prática.

De forma geral, a concretização dos direitos à acessibilidade e mobilidade urbana está vinculada à cultura de eliminação e superação das barreiras urbanísticas, que impedem o pleno gozo de outros direitos humanos pelas pessoas com deficiência ou mobilidade reduzida. A afirmativa segundo a qual os direitos à acessibilidade e mobilidade no bojo das cidades são verdadeiros instrumentos à colocação prática de outros direitos fundamentais se faz correta, ao passo em que garantir tais direitos, além de possibilitar a organização dos grupos em questão para reivindicá-los de forma coletiva, também serve de ponte para a concretização dos direitos de cidadania.

A experiência histórica da cidade de Franca, no interior do estado de São Paulo, no tratamento jurídico, político e institucional dos direitos das pessoas com deficiência ou 
mobilidade reduzida, notadamente aqueles que guardam relações com o urbanismo, apresenta situações que antigamente se tornavam absurdas do ponto de vista da efetivação dos direitos humanos. Não havia acessibilidade ou condições de mobilidade em prédios públicos essenciais para o exercício de outros direitos fundamentais, o que englobava os prédios do Ministério Público, do Poder Judiciário ou do Museu Histórico, o que resvalava necessariamente nos direitos de acesso à informação e tutela processual individual ou coletiva, de acesso à justiça e de acesso à cultura, respectivamente.

Atualmente, ainda que de maneira lenta e paulatina, a cidade interiorana de Franca aparece na condição de colecionadora de importantes instrumentos normativos que buscam operar alterações na filosofia social dos munícipes, formulando um cenário de respeito às diferenças, e possibilitar às pessoas com deficiência ou mobilidade reduzida o acesso a serviços e produtos básicos, como forma de garantia de seus direitos humanos. A partir da análise dos instrumentos normativos e principais políticas de acessibilidade e mobilidade no ambiente urbano francano, faz-se possível tecer críticas no sentido de que, embora as intenções sejam boas, há notória falta de políticas públicas e normas específicas que sejam pertinentes a outros tipos de deficiência, excetuando as pessoas com deficiência física, que aparentam ser as pessoas para as quais a atenção do poder público está primordialmente voltada.

Em conclusão, pode-se afirmar categoricamente que a introdução de instrumentos urbanísticos que possibilitem o usufruto dos direitos à acessibilidade e mobilidade urbana representa medida de efetividade dos direitos humanos e da cidadania das pessoas com deficiência ou mobilidade reduzida. Em sentido contrário, sob a ótica das pessoas que não são pertencentes a quaisquer desses grupos, certo é que as alterações urbanísticas não ocasionam qualquer mudança no exercício de seus direitos. Significa dizer que há uma relação simbiótica e de duplo ganho: enquanto para as pessoas que não possuem deficiência ou mobilidade reduzida as medidas de acessibilidade e mobilidade urbana representam formas de fomento ao direito à cidade e ao direito de conviver com a diversidade, para as pessoas pertencentes aos grupos em questão constituem medidas essenciais para o acesso a outros direitos humanos e seu consequente exercício. 


\section{Referências bibliográficas}

ADORNO, Rubens de Camargo Ferreira. Capacitação solidária: um olhar sobre os jovens e sua vulnerabilidade social. São Paulo: Associação de Apoio ao Programa Capacitação Solidária - AACPS, 2001.

APPIO, Eduardo. Controle judicial das políticas públicas no Brasil. Curitiba: Juruá, 2006.

BRASIL. Lei $\mathrm{n}^{\circ}$. 13.146, de 6 de julho de 2015. Institui a Lei Brasileira de Inclusão da Pessoa com Deficiência (Estatuto da Pessoa com Deficiência). Disponível em: http://www.planalto.gov.br/ccivil_03/_ato2015-2018/2015/lei/113146.htm. Acesso em: 29 ago 2019.

CARVALHO, Anivaldo José de. Importância do transporte público e da acessibilidade como meios de acesso a direito de cidadania das pessoas com deficiência: o caso dos cadeirantes de Franca-SP. 2017. Dissertação (Mestrado Profissional em Políticas Públicas) - Faculdade de Ciências Humanas e Sociais, Universidade Estadual Paulista, Franca.

COMÉRCIO DA FRANCA. Fórum, delegacia ou museu: proibidos para deficientes. Jornal Comércio da Franca, 2007. Disponível em: https://www.gcn.net.br/noticias/24021/franca/2018/4/m. Acesso em: 4 ago 2019.

FRANCA. Lei Complementar $\mathrm{n}^{\mathrm{o}}$ 271, de 25 de maio de 2016. Acrescenta dispositivo a Lei Complementar $n^{o}$ 131/2008, que altera a Lei Complementar $n^{o}$ 125/2007, e dá outras providências. Disponível em: https://franca.sp.leg.br/legislacao/lei-complementar-no-271-de25-de-maio-de-2016. Acesso em: 4 ago 2019.

FRANCA. Lei Complementar $\mathrm{n}^{\circ} 314$, de 16 de abril de 2019. Dispõe sobre o Plano Municipal de Mobilidade Urbana do Município de Franca - SP, e dá outras providências. Disponível em: https://franca.sp.leg.br/legislacao/lei-complementar-no-314-de-16-de-abril-de-2019. Acesso em: 4 ago 2019.

FRANCA. Lei $\mathrm{n}^{\circ}$ 6.621, de 14 de julho de 2006. Dispõe sobre rebaixamento das guias de calçadas, para trânsito de cadeirantes, como medida de acessibilidade aos deficientes físicos. Disponível em: https://franca.sp.leg.br/legislacao/lei-no-6621-de-14-de-julho-de-2006. Acesso em: 4 ago 2019.

MORRIS, J. M.; DUMBLE, P.; WIGAN, M. Accessibility indicator for transport planning. Transportation Research A, v.13, n.2, p.91-109, 1979.

SÁNCHEZ RUBIO, David. Crítica a una cultura estática y anestesiada de derechos humanos. Por una recuperación de las dimensiones constituyentes de la lucha por los derechos. Derechos y libertades, Madrid, n.33, p.99-133, 2015.

SOUTO, Leonardo Fernandes. Acesso à informação digital para portadores de necessidades especiais em bibliotecas universitárias: questão de ética de cidadania. Cadernos BAD, Revista da Associação Portuguesa de Bibliotecários, Arquivistas e Documentalistas, p.73-83, 2006. 